\title{
Experimental and Modeling Study on Adiabatic Two-phase Expansion in a Cylinder
}

\author{
Hiroshi Kanno*and Naoki Shikazono** \\ *Railway Technical Research Institute, 2-8-38 Hikari-cho Kokubunji-shi, Tokyo, Japan \\ ** The University of Tokyo, 4-6-1 Komaba Meguro-ku, Tokyo, Japan
}

\begin{abstract}
In the present study, visualization and measurement of two-phase adiabatic expansion in a cylinder with moving piston are carried out. Experimental setup with piston and cylinder which mimics reciprocating expander was constructed and boiling phenomenon is visualized. The difference between measured and quasi-static pressures becomes larger as piston velocity is increased. With the decrease of piston diameter, agitation of the liquid phase becomes stronger and adiabatic efficiency becomes closer to that of the quasi-static state. The adiabatic efficiency is almost independent on the initial fluid temperature. Finally, a model to predict pressure change in two-phase expansion process is proposed and the model can predict adiabatic efficiency within the range of about $\pm 2.5 \%$ accuracy. From the model prediction, it is shown that the uniformity of the liquid phase temperature distribution is the key factor for improving the adiabatic efficiency.
\end{abstract}

Keywords: Two-phase expansion, Adiabatic efficiency, Boiling

\section{Introduction}

In recent years, waste heat recovery systems using heat cycles have been widely investigated in order to improve the energy utilization efficiency. To convert moderate or low temperature heat into power, trilateral cycle [1-4] attracts large attentions because of its high potential of exergy recovery. In the trilateral cycle, working fluid is pressurized and kept as a single liquid phase during the heating process. Temperature profile matching can be improved during the heat exchange between heat source and liquid phase working fluid, which results in the exergy loss reduction. Therefore, exergy efficiency of the trilateral cycle can be theoretically the highest among other heat cycles. In the expansion process of the trilateral cycle, working fluid is flashed and becomes liquid-vapor two-phase. This two-phase expander is one of the key components to realize the trilateral cycle system.

For two-phase expansion or wet-vapor expansion, the volumetric expander is preferable from the view point of erosion durability. There are several studies of wet-vapor expansion such as Lysholm turbine, scroll or reciprocating expanders [5-11]. Ohman et al. [5] investigated Lysholm turbine and reported that peak efficiency is sensitive to the inlet vapor condition, and that further investigation for the inlet two phase condition is needed. Bao et al. [7] reviewed the working fluids and the capacity, cost, advantages of several kinds of expanders, and reported that reciprocating piston expander has the advantage of adaptability for variable working conditions and tolerance for two-phase expansion. Smith et al. [8-10] estimated the performance and cost of trilateral flash cycle using Lysholm twin screw turbine. They 
reported that the adiabatic efficiency of the expander can reach $70 \%$, and that the trilateral flash cycle can produce 1.8 times larger output power than simple Rankine cycle for hot steam of 100-200 ${ }^{\circ} \mathrm{C}$. Oreijah et al. [11] conducted an experimental study to compare trilateral flash cycle and ORC using screw expanders. They reported that the trilateral cycle shows a larger power generation than ORC, but the expander can be operated at lower rotational speed in ORC than in trilateral cycle. Steffen et al. [12] proposed a novel trilateral cycle using cyclone separation and reciprocating expander, and simulated the influence of injection timing, material of cyclone, the size and frequency of reciprocating expander. They concluded that effective thermal insulation of the cyclone wall is important, and found that large stroke volume and engine speed decrease the isentropic efficiency of expander due to the influence of injection timing. They also reported that the cycle using water as a working fluid has 1.35 to 1.7 times higher exergy efficiency than the ORCs ever studied.

A two-phase expansion in adiabatic condition is called as flash evaporation. Flash evaporation phenomenon has been studied in the field of refrigeration, desalination, nuclear reactor, jet nozzle or other chemical processes. Yan et al. [13-14] conducted an experimental study on static and circulatory flash evaporation and investigated the steam-carrying effect. Saury et al. [15] studied flash evaporation of water film and proposed a correlation between the dimensionless maximum mass flow rate, dimensionless initial temperature, depressurization rate, superheat and initial water height. Mutair et al. [16] conducted an experimental study on flash evaporation from a superheated water jet. They concluded that the inflection point and evaporation end heights can be normalized with the nozzle diameter and can be correlated with Weber, Froude and Jacob numbers.

All the above flash evaporation studies were carried out with the flash chamber i.e. in a constant volume condition without taking out work from the system. Thus, research on adiabatic two-phase expansion to generate output power in an expander is still limited. Especially, the mechanism of adiabatic efficiency reduction in two-phase expansion is not fully investigated. Most of the studies on flash "evaporation" deal with the depressurization rate as an input parameter by controlling the pressure of vacuum tank and evaluate the influence of the depressurization rate against time [14-15]. However, when obtaining work from flash "expansion", the inner pressure should be kept as high as possible, i.e. it is desirable to keep the depressurization rate as low as possible. In addition, the influence of expansion velocity on the pressure degradation is of interest. In this study, working fluid is expanded and work is generated by the piston in a thermally insulated cylinder. Boiling is visualized by the high speed micro scope. Output power is obtained from the measured $P-V$ diagram. Adiabatic efficiency is evaluated and the effects of piston velocity and piston diameter are evaluated. Finally, a model to predict pressure change in a two-phase expansion process is proposed. To simplify the phenomena, one dimensional thermal conduction model is used and the temperature distribution in the cylinder is calculated. The agitation effect of boiling on adiabatic efficiency is also investigated. 


\begin{tabular}{|c|c|}
\hline \multicolumn{2}{|c|}{ NOMENCLATURE } \\
\hline Bo & Bond number \\
\hline$c_{\mathrm{p}}$ & liquid heat capacity $(\mathrm{kJ} / \mathrm{kgK})$ \\
\hline$d$ & constant value \\
\hline$D$ & diameter $(\mathrm{mm})$ \\
\hline$g$ & gravity acceleration $\left(\mathrm{m} / \mathrm{s}^{2}\right)$ \\
\hline$h$ & heat transfer coefficient $\left(\mathrm{W} / \mathrm{m}^{2} \mathrm{~K}\right)$ \\
\hline $\mathrm{Ja}$ & Jakob Number \\
\hline$l_{v}$ & latent heat $(\mathrm{kJ} / \mathrm{kg})$ \\
\hline$m$ & mass $(\mathrm{kg})$ \\
\hline$n$ & coefficient \\
\hline$p$ & pressure (MPa) \\
\hline$Q$ & heat $(\mathrm{kJ})$ \\
\hline$r$ & ratio \\
\hline$t$ & time (s) \\
\hline$S$ & interface area $\left(\mathrm{m}^{2}\right)$ \\
\hline$T$ & temperature $\left({ }^{\circ} \mathrm{C}, \mathrm{K}\right)$ \\
\hline$u$ & specific internal energy $(\mathrm{kJ} / \mathrm{kg})$ \\
\hline$v$ & velocity $(\mathrm{mm} / \mathrm{s})$ \\
\hline$V$ & volume $\left(\mathrm{m}^{3}\right)$ \\
\hline W & work (kJ) \\
\hline \multicolumn{2}{|c|}{ Greek symbols } \\
\hline$a$ & acceleration $\left(\mathrm{mm} / \mathrm{s}^{2}\right)$ \\
\hline$\beta$ & agitation factor \\
\hline$\Delta$ & difference \\
\hline$\lambda$ & thermal conductivity (W/mK) \\
\hline$\mu$ & viscosity (Pa s) \\
\hline$\rho$ & density $\left(\mathrm{kg} / \mathrm{m}^{3}\right)$ \\
\hline$\sigma$ & surface tension $(\mathrm{mN} / \mathrm{m})$ \\
\hline$\eta$ & efficiency (\%) \\
\hline \multicolumn{2}{|c|}{ Subscripts } \\
\hline 0 & initial condition \\
\hline $1,2,3$ & number of coefficient \\
\hline agi & agitated \\
\hline ave & average \\
\hline b & bubble \\
\hline cyl & cylinder \\
\hline eff & effective \\
\hline eq & equilibrium \\
\hline $\exp$ & expansion \\
\hline $\mathrm{fl}$ & working fluid \\
\hline gen & generated \\
\hline inter & interface \\
\hline ise & isentropic(quasi-static) \\
\hline liq & liquid \\
\hline $\max$ & maximum \\
\hline $\mathrm{p}$ & piston \\
\hline sat & saturate \\
\hline & bottom stainless plate \\
\hline & total \\
\hline & vapor \\
\hline - & difference \\
\hline \multicolumn{2}{|c|}{ Superscripts } \\
\hline & $\begin{array}{l}\text { dimensionless quantity } \\
\text { previous time step }\end{array}$ \\
\hline
\end{tabular}




\section{Experimental setup and procedure}

\subsection{Experimental setup}

Figure 1 shows the insulated cylinder for two-phase expansion experiment. In this study, water is used as the working fluid. The cylinder is a double pipe made of polycarbonate. The bottom of the cylinder is made of thin stainless plate with thickness of $0.6 \mathrm{~mm}$. The working fluid and the setup are heated up to operating temperature by hot air, and then the double tube is vacuumed by a vacuum pump for thermal insulation before the expansion experiment. The temperature of liquid and vapor phases are measured by thermo-couples attached to the piston and the bottom of the cylinder. The pressure in the cylinder is measured by the pressure sensor embedded in the piston. Indicated work is obtained from a $P$ - $V$ diagram.

Figure 2 shows the schematic of the experimental setup and figure 3 presents the image of the experimental setup.. Table 1 shows the physical properties of the stainless plate and the cylinder. Table 2 shows the experimental condition. A polycarbonate pipe with inner diameters of $D_{\mathrm{p}}=38,44$ and $55 \mathrm{~mm}$ were used as the cylinder. During the expansion process, the piston is accelerated with a constant acceleration of $\alpha_{\mathrm{p}}$ and moved with constant velocity of $v_{\mathrm{p}}$ and decelerated with $\alpha_{\mathrm{p}}$. The setup can be heated by the hot air from the heater No. 2 and is insulated by the vacuum pump No. 3. Heating and vacuum insulation are conducted by the cross valves No. 4, 5, 6, 7 and 8. The piston is actuated by the linear actuator No. 9 and its displacement is measured by the pulse counter No. 10. Boiling phenomenon in the cylinder is visualized by the high speed microscope No. 11 .

The two-phase expansion experiments are carried out in the following procedure. First, the piston is initially set at $z_{\mathrm{p}}=z_{0}$ by the linear actuator (EZC6D030M-K, Oriental Motor). Then, by operating the cross valves No.4, 5 and 6 , the hot air from the heater (SD-2-2, Sakaguchi E.H VOC) is introduced to the insulation chamber (inside double-pipe cylinder) and the setup is warmed up. During this procedure, the flash chamber (test section) is connected to the vacuum pump (GLD-201B, Ulvac) by switching the cross valve 7 to purge the air in the test section. When the pressure in the cylinder (test section) becomes smaller than $0.001 \mathrm{MPa}$, the cross valves No. 7 and 8 are switched, and then the test section is connected to the syringe (1050-TLL, GL Science). After the working fluid of $m_{0}[\mathrm{~kg}]$ is introduced to the test section from the syringe, cross valve No. 7 is switched to isolate the test section. During and after these procedures, hot air is introduced to the insulation chamber (bottom of the cylinder and inside the double tube) to heat the working fluid and the pipe walls. The temperature of hot air is controlled by the heat regulator (E5CB-Q1TC, Omron) and the solid state relay (G3PA-210B-VDDC5-24, Omron). When the liquid temperature $T_{\text {liq }}$ reaches initial operating temperature $T_{0}$, hot air supply is stopped by switching cross the valve No. 4 . Then, the cross valves No.5 and 6 are switched immediately and remained hot air is withdrawn to the vacuum pump. In this procedure the setup is thermally insulated by vacuum insulation. Then, the piston is moved by the linear actuator motor. The pressure inside the cylinder is measured by the pressure sensor (PHS-B-200KP, Kyowa), and its signal is amplified by the dynamic strain amplifier (DMP911B, Kyowa). The temperature of liquid and vapor phase is measured by sheath type thermocouples (1HKN033, Chino) with outer diameter of $0.3 \mathrm{~mm}$. The piston displacement is observed by the pulse counter (CNT-3921-E-DF, Coco Research). All analog data are recorded on the midi-logger (GL7000, Graphtec) with the sampling frequency of $10 \mathrm{msec}$. Boiling phenomenon is visualized and recorded by the high speed micro scope (VW-9000, Keyence) with the frame speed of $1000 \mathrm{fps}$. 


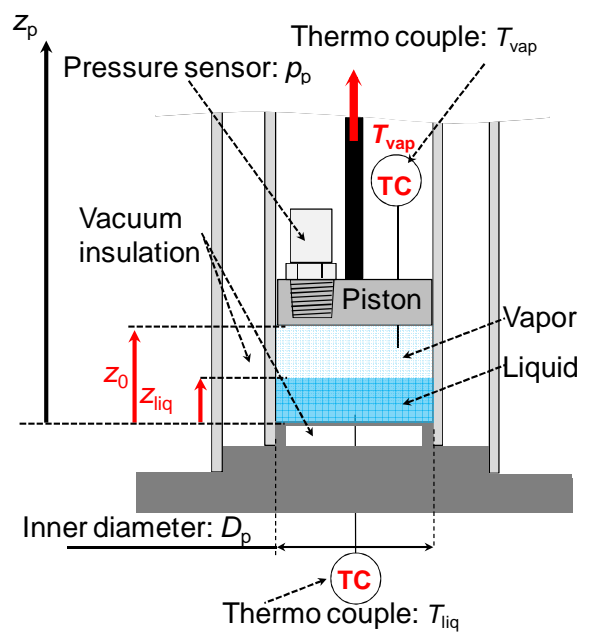

Fig. 1 Cross section of the cylinder and the piston.

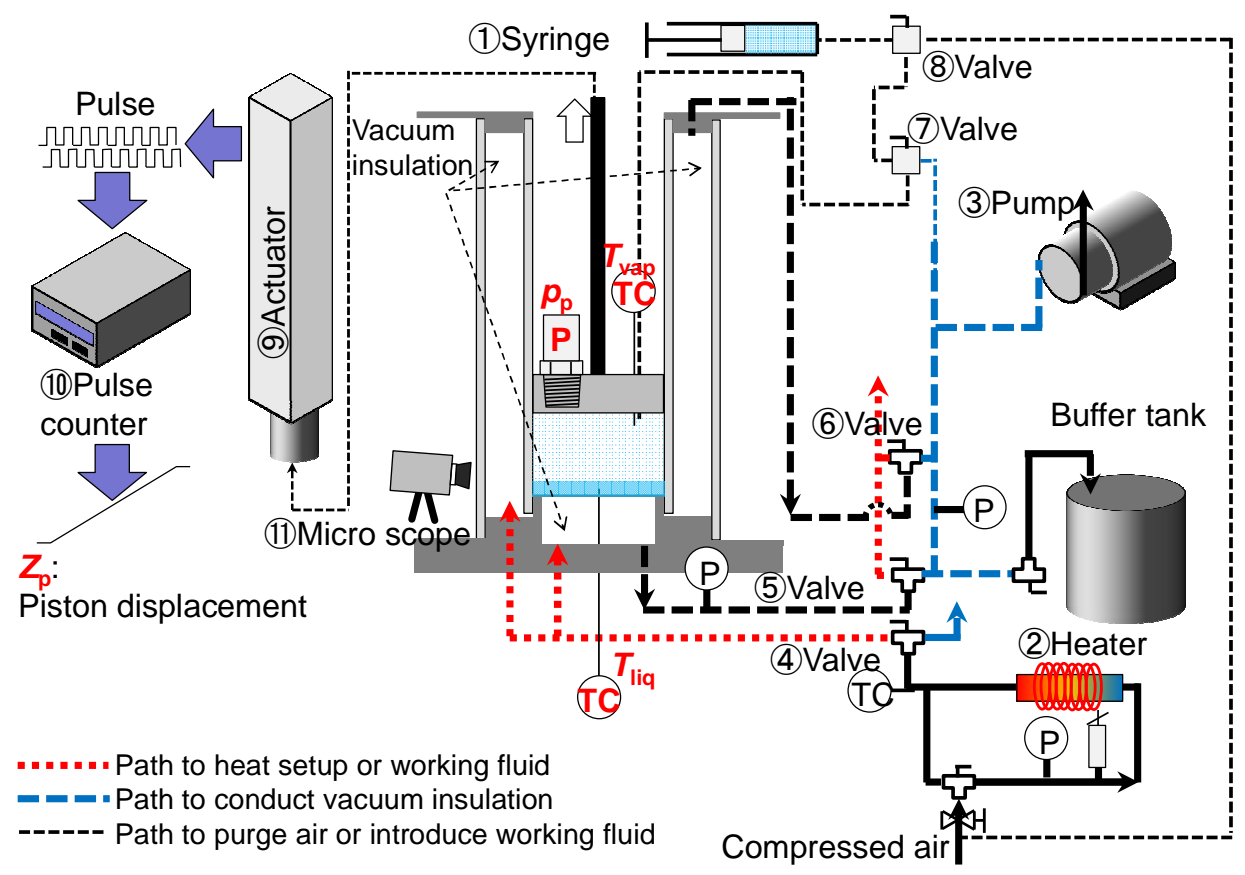

Fig. 2 Schematic of the experimental setup 


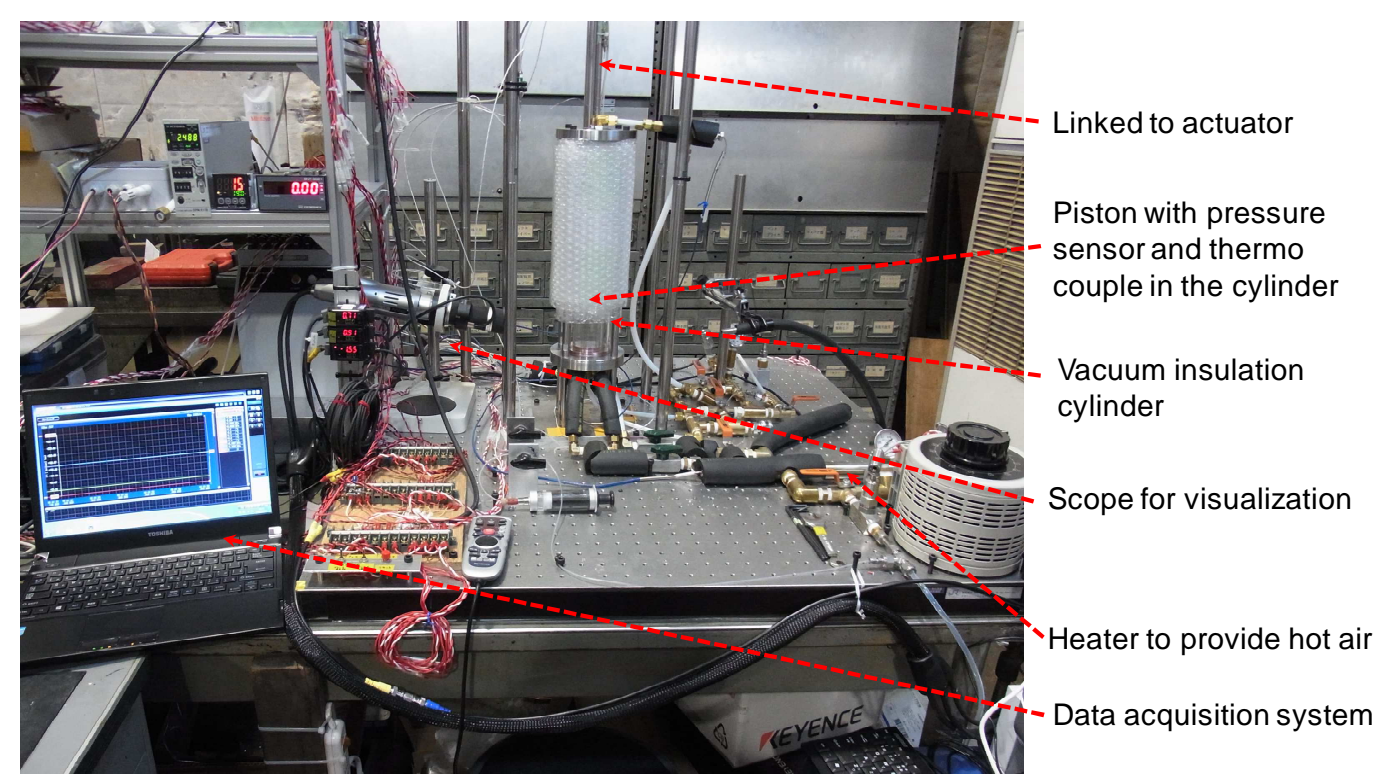

Fig. 3 Image of the experimental setup

Table 1 Physical properties of stainless plate and cylinder

\begin{tabular}{ccc}
\hline & $\begin{array}{c}\text { Stainless plate } \\
\text { (SUS304) }\end{array}$ & $\begin{array}{c}\text { Cylinder } \\
\text { (polycarbonate) }\end{array}$ \\
\hline$\rho\left(\mathrm{kg} / \mathrm{m}^{3}\right)$ & 9790 & 1200 \\
$C(\mathrm{~kJ} / \mathrm{kgK})$ & 0.59 & 1.05 \\
\hline
\end{tabular}

Table 2 Experimental condition

\begin{tabular}{cc}
\hline Parameter & Range \\
\hline$T_{0}\left({ }^{\circ} \mathrm{C}\right)$ & $80-120$ \\
$z_{\text {liq }}(\mathrm{mm})$ & 6 \\
$z_{0}(\mathrm{~mm})$ & 9 \\
$r_{\exp }$ & 20 \\
$D_{\mathrm{p}}(\mathrm{mm})$ & $38,44,55$ \\
$a_{\mathrm{p}}\left(\mathrm{mm} / \mathrm{s}^{2}\right)$ & 833 \\
$v_{\mathrm{p}}(\mathrm{mm} / \mathrm{s})$ & $1-192$ \\
\hline
\end{tabular}

\subsection{Calibration of average liquid temperature and heat dissipation}

Figure 4 shows the transferred heat to the experimental setup. This experimental setup is insulated by a vacuum pump. However, heat dissipation cannot be neglected when the piston velocity is low. In addition, the measured liquid temperature is affected by the local bubble generated by boiling, so average liquid temperature cannot be measured from a single thermos-couple. To estimate the influence of heat dissipation and to obtain average liquid temperature, following calibration procedure is conducted. 


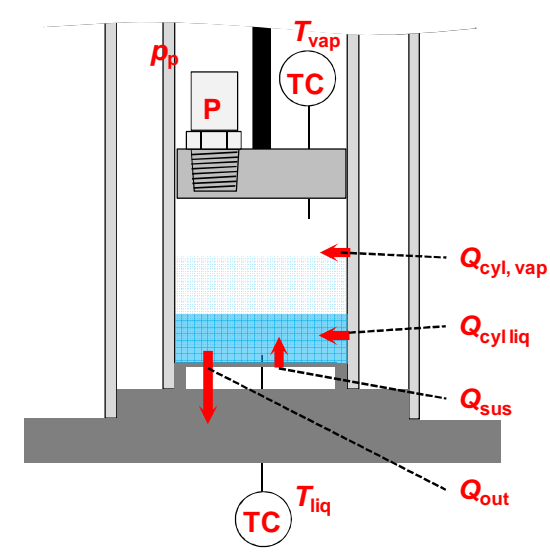

Fig. 4 Heat dissipation and influx

The energy balance in the liquid phase is calculated by Eq. (1). The heat inputs from stainless plate and cylinder wall are expressed as Eqs. (2) and (3). The temperatures of stainless plate and cylinder wall are calculated by Eqs. (4) and (5).

$$
\begin{gathered}
m_{\text {liq }} C_{\mathrm{p}} \mathrm{d} T_{\text {liq,ave }}=\mathrm{d} m_{\text {liq }} l_{\mathrm{v}}+\delta Q_{\text {sus }}+\delta Q_{\text {cyl liq }} \\
+\delta Q_{\text {out }}
\end{gathered}
$$

The effect of heat dissipation is obtained by measuring the liquid temperature during the calibration experiment. Fig. 5 shows the liquid temperature change for $D_{\mathrm{p}}=44 \mathrm{~mm}$ and $T_{0}=100{ }^{\circ} \mathrm{C}$. From the temperature change during the calibration experiment, the heat dissipation is calculated by Eq. (6).

$\delta Q_{\text {out }}=m_{\text {liq }, 0} C_{\mathrm{p}} \mathrm{d} T_{\text {liq }}$ 


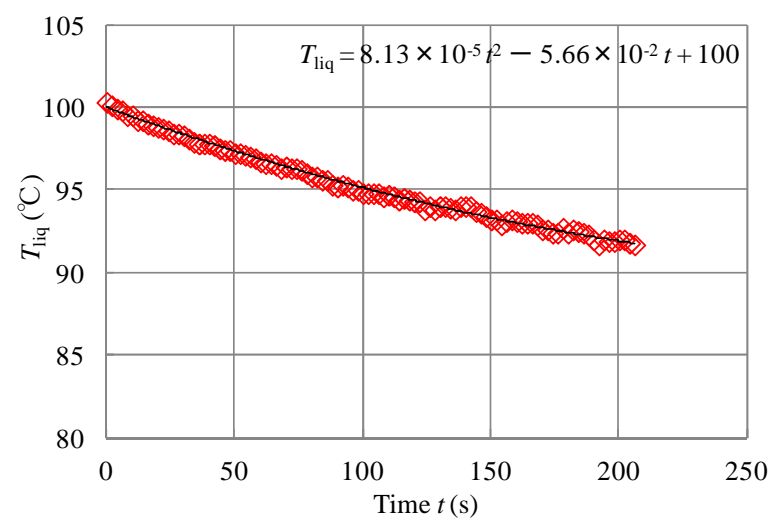

Fig. 5 Liquid temperature change for $D_{\mathrm{p}}=44 \mathrm{~mm}$ and $T_{0}$

$=100{ }^{\circ} \mathrm{C}$.

From Eqs. (1), (2), (3) and (6), Eq. (7) is obtained. In Eq. (7),$d$ is a integral constant determined by the initial condition, i.e. $T_{\text {liq,ave }}=T_{0}$ and $Q_{\text {sus }}=Q_{\text {cyll liq }}=Q_{\text {out }}=0$ at $t=0$.

$$
\begin{aligned}
\int \frac{C_{\mathrm{p}}}{l_{\mathrm{v}}} \mathrm{d} T_{\text {liq,ave }}= & \ln \left(m_{\text {liq }, 0}\right) \\
& -\frac{Q_{\text {sus }}+Q_{\text {cyl,liq }}+Q_{\text {out }}}{m_{\text {liq }} l_{\mathrm{v}}}-d
\end{aligned}
$$

The volume change of liquid phase is very small compared to that of the vapor phase. Therefore, the vapor volume is expressed as Eq. (8). In Eq. (8), $m$ ' liq is defined as the liquid mass of the previous time step. Mass of liquid phase is obtained from Eq. (9). Vapor density is obtained using REFPROP ver. 9.0[17].

$V_{\text {vap }}=V_{\text {cyl }}-V_{\text {liq }}=V_{\text {cyl }}-\frac{m_{\text {liq }}^{\prime}}{\rho_{\text {liq }}}$
$m_{\text {liq }}=m_{0}-m_{\text {vap }}=m_{0}-V_{\text {vap }} \rho_{\text {vap }}$

The average liquid temperature $T_{\text {liq,ave }}$ is calculated from Eqs. (7) and (9). Fig. 6 shows an example of the temperature changes during the two-phase expansion experiment. The temperature difference between liquid and vapor is defined by using the average liquid temperature and the measured vapor temperature. Internal energy of the liquid phase is obtained from the average liquid temperature. Therefore, transferred heat from the cylinder wall to the vapor phase is obtained from Eq. (10). Finally, total transferred heat $Q_{\text {total }}$ is obtained from Eq. (11).

In Eqs. (2) and (3), the value of the heat transfer coefficient $h$ is tuned so that the liquid and bottom-plate temperatures become close to the equilibrium temperature when the vapor and liquid phases reach equilibrium, as shown in Fig. 6. In this study, the heat transfer coefficient is set to 4000 . 


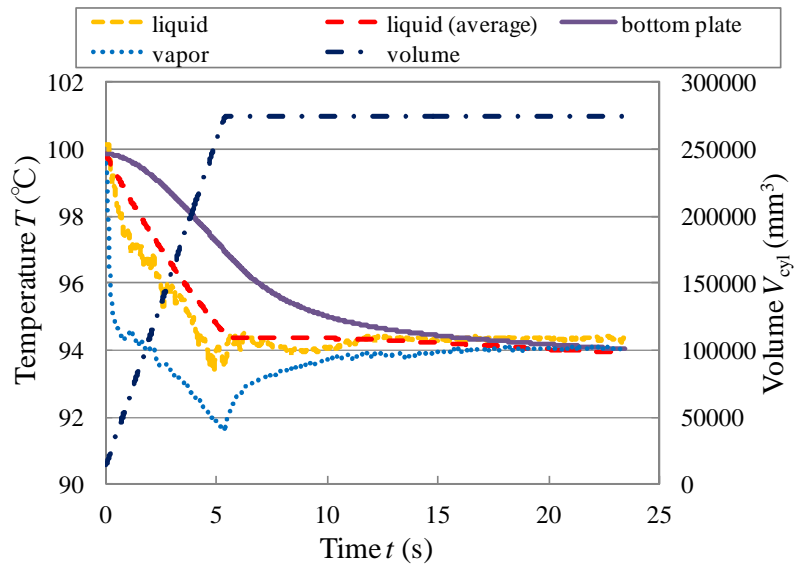

Fig. 6 Temperature changes during the two-phase expansion experiment for $D_{\mathrm{p}}=44 \mathrm{~mm}, T_{0}=100{ }^{\circ} \mathrm{C}, v_{\mathrm{p}}=$ $32 \mathrm{~mm} / \mathrm{s}$.

$$
\begin{aligned}
m_{0} u_{0}=m_{\text {liq }} u_{\text {liq }} & +m_{\text {vap }} u_{\text {vap }}+\int p_{\mathrm{p}} \mathrm{d} V_{\text {cyl }} \\
& -\left(Q_{\text {sus }}+Q_{\text {cyl,liq }}+Q_{\text {cyl,vap }}\right. \\
& \left.+Q_{\text {out }}\right) \\
Q_{\text {total }}=Q_{\text {sus }}+ & Q_{\text {cyl liq }}+Q_{\text {cyl,vap }}+Q_{\text {out }}
\end{aligned}
$$

\subsection{Definition of adiabatic efficiency}

The adiabatic efficiency is defined as the ratio of the measured indicated work to that of the quasi-static expansion, as shown in Eq. (12). In this study, the total transferred heat is taken into account when calculating the quasi-static work. If the piston velocity is very slow, i.g. $v_{\mathrm{p}}=1$ or $2 \mathrm{~mm} / \mathrm{s}$, the effect of total transferred heat on the adiabatic efficiency cannot be neglected. For example, figure 7 shows the effect of total transferred heat on quasi-static expansion for $D_{\mathrm{p}}=$ $44 \mathrm{~mm}, T_{0}=100^{\circ} \mathrm{C}, v_{\mathrm{p}}=2 \mathrm{~mm} / \mathrm{s}$. Pressure change of quasi-static expansion considering total transferred heat becomes lower than the case without considering it.

$\eta_{\exp }=\frac{W_{\text {exp }}}{W_{\text {ise }}}$ 


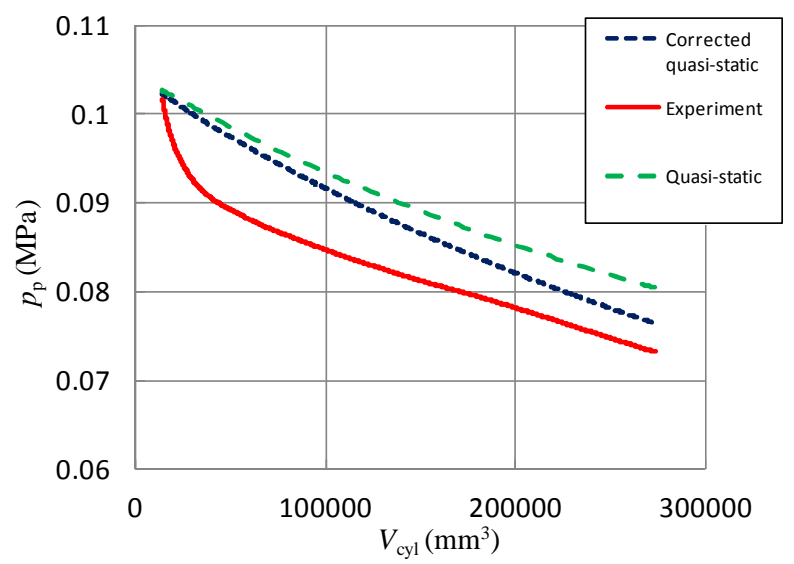

Fig. 7 The effect of heat dissipation on quasi-static expansion for $D_{\mathrm{p}}=44 \mathrm{~mm}, T_{0}=100{ }^{\circ} \mathrm{C}, v_{\mathrm{p}}=2 \mathrm{~mm} / \mathrm{s}$.

\section{Experimental results}

\subsection{Visualization}

Figure 8 shows the visualization results for $T_{0}=100{ }^{\circ} \mathrm{C}, D_{\mathrm{p}}=44 \mathrm{~mm}$. The numbers of boiling bubbles increase as the piston velocity is increased. Many bubbles are generated from the bottom of the cylinder, and the liquid phase is strongly agitated by the bubbles when the piston velocity is larger than $100 \mathrm{~mm} / \mathrm{s}$. Most bubbles are generated from the edge of the cylinder or the stem of thermo-couple attached at the center of the cylinder. Figure 9 shows the visualization results for $T_{0}=100{ }^{\circ} \mathrm{C}, v_{\mathrm{p}}=128 \mathrm{~mm} / \mathrm{s}$. In the case of $D_{\mathrm{p}}=38 \mathrm{~mm}$, it seems that the interface between the liquid and vapor temperature is raised by the bubbles. It is considered that the liquid phase is agitated more strongly in the case of small piston diameter.

(a)

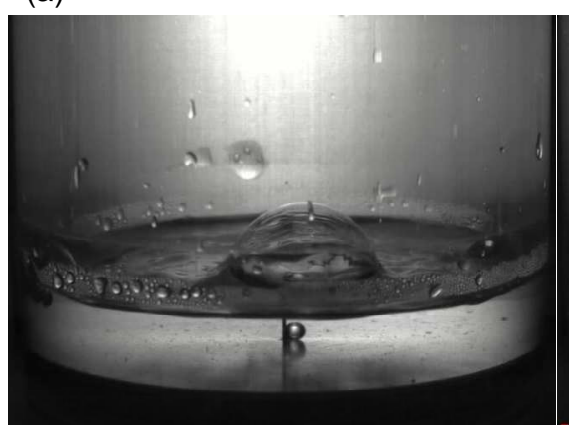

(b)

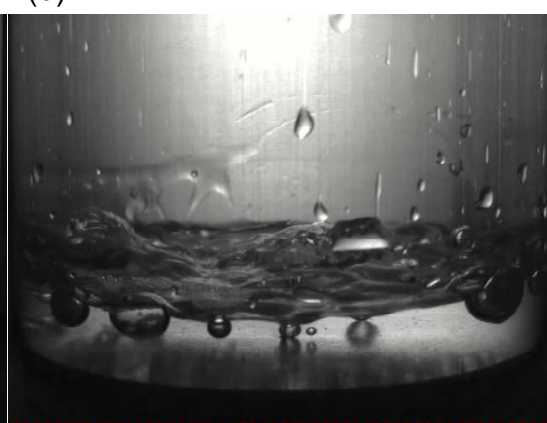

(c)

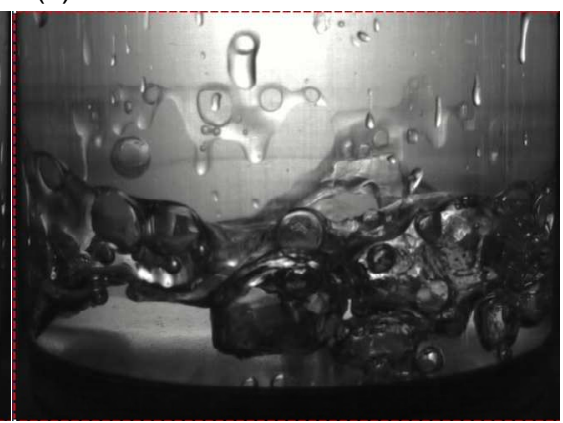

Fig. 8 Visualization results for $T_{0}=100{ }^{\circ} \mathrm{C}, D_{\mathrm{p}}=44 \mathrm{~mm}$. (a) $v_{\mathrm{p}}=8 \mathrm{~mm} / \mathrm{s}$, (b) $v_{\mathrm{p}}=32 \mathrm{~mm} / \mathrm{s}$ and (c) $v_{\mathrm{p}}=128 \mathrm{~mm} / \mathrm{s}$. 
(a)

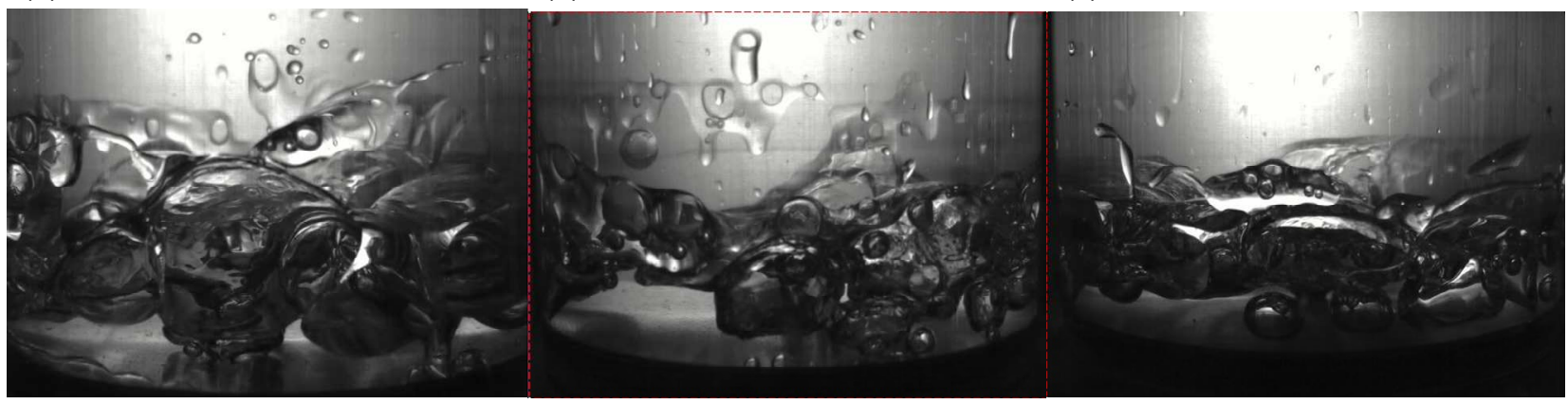

Fig. 9 Visualization results for $T_{0}=100{ }^{\circ} \mathrm{C}, v_{\mathrm{p}}=128 \mathrm{~mm} / \mathrm{s}$. (a) $D_{\mathrm{p}}=38 \mathrm{~mm}$, (b) $D_{\mathrm{p}}=44 \mathrm{~mm}$ and (c) $D_{\mathrm{p}}=55 \mathrm{~mm}$.

\section{2 $P$ - $V$ diagram and adiabatic efficiency}

Figure 10 shows the $P$-V diagram for $D_{\mathrm{p}}=44 \mathrm{~mm}, T_{0}=100{ }^{\circ} \mathrm{C}$. As a whole, the measured pressures are lower than the quasi-static pressure. At the beginning of the expansion, the measured pressure decreases immediately and then the pressure decline becomes moderate. The difference between measured and quasi-static pressures increases with the increase of piston velocity. It is considered that this pressure reduction is caused by the lack of phase change due to high-piston velocity. Figure 11 shows the $P$ - $V$ diagram for $v_{\mathrm{p}}=128 \mathrm{~mm} / \mathrm{s}, T_{0}=100{ }^{\circ} \mathrm{C}$ and $D_{\mathrm{p}}=38,44,55 \mathrm{~mm}$. The difference between the measured and quasi-static pressures becomes larger with the increase of piston diameter. Figure 12 shows the adiabatic efficiency for $v_{\mathrm{p}}=1-192 \mathrm{~mm} / \mathrm{s}, T_{0}=100{ }^{\circ} \mathrm{C}$ and $D_{\mathrm{p}}=38,44,55 \mathrm{~mm}$. The adiabatic efficiency decreases as the piston velocity and the piston diameter are increased. From the boiling visualization, boiling bubbles are mostly generated from the corner of the cylinder. Therefore, agitation effect of the liquid phase is stronger for the case of smaller piston diameter. It is clearly seen that this liquid phase agitation strongly affects the adiabatic efficiency.

As shown in Fig. 6, the temperature difference between the average liquid temperature and the measured vapor temperature takes maximum at the beginning of expansion. Figure 13 shows how adiabatic efficiency depends on the maximum temperature difference for $v_{\mathrm{p}}=1-192 \mathrm{~mm} / \mathrm{s}, T_{0}=100{ }^{\circ} \mathrm{C}$ and $D_{\mathrm{p}}=38,44,55 \mathrm{~mm}$. The adiabatic efficiency is small when the maximum temperature difference is large. In this condition, the liquid and vapor phase is not in equilibrium, i.e. the hot liquid and cold vapor exist in the cylinder, so the pressure in the cylinder is reduced because of the lack of phase change.

Figure 14 and 15 show $P$ - $V$ diagram and adiabatic efficiency for $v_{\mathrm{p}}=128 \mathrm{~mm} / \mathrm{s}, D_{\mathrm{p}}=44 \mathrm{~mm}$, respectively. The pressure difference between measured and quasi-static pressures increases as the initial temperature increases. The adiabatic efficiency is almost constant regardless of the initial temperatures. 


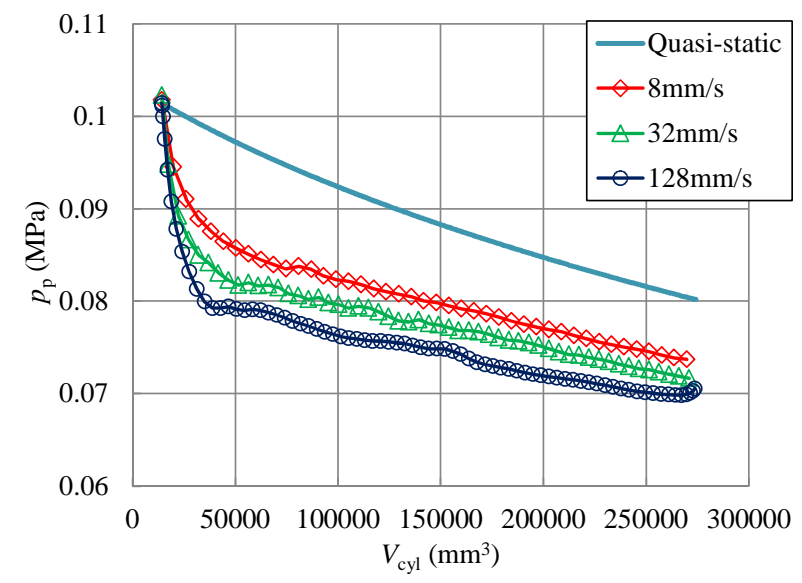

Fig. $10 P-V$ diagram for $D_{\mathrm{p}}=44 \mathrm{~mm}, T_{0}=100{ }^{\circ} \mathrm{C}$ and $v_{\mathrm{p}}=8,32,128 \mathrm{~mm} / \mathrm{s}$.

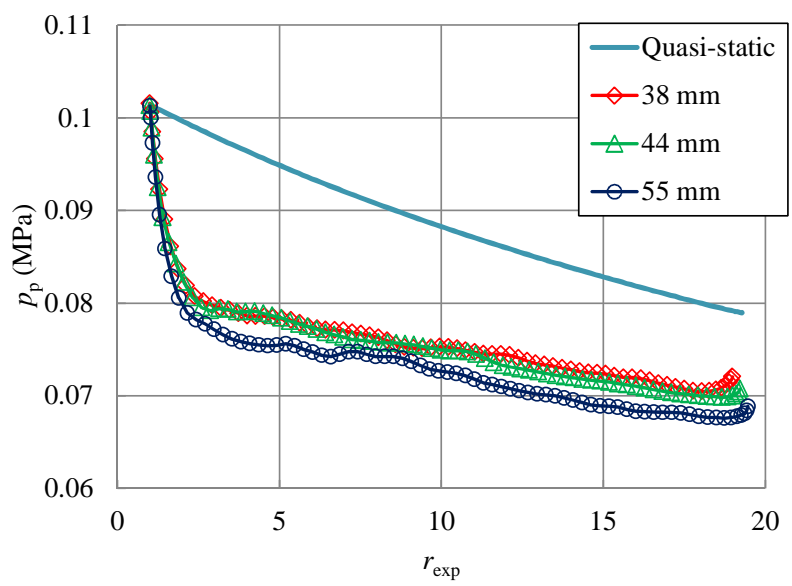

Fig. $11 P-V$ diagram for $v_{\mathrm{p}}=128 \mathrm{~mm} / \mathrm{s}, T_{0}=100{ }^{\circ} \mathrm{C}$ and $D_{\mathrm{p}}=38,44,55 \mathrm{~mm}$.

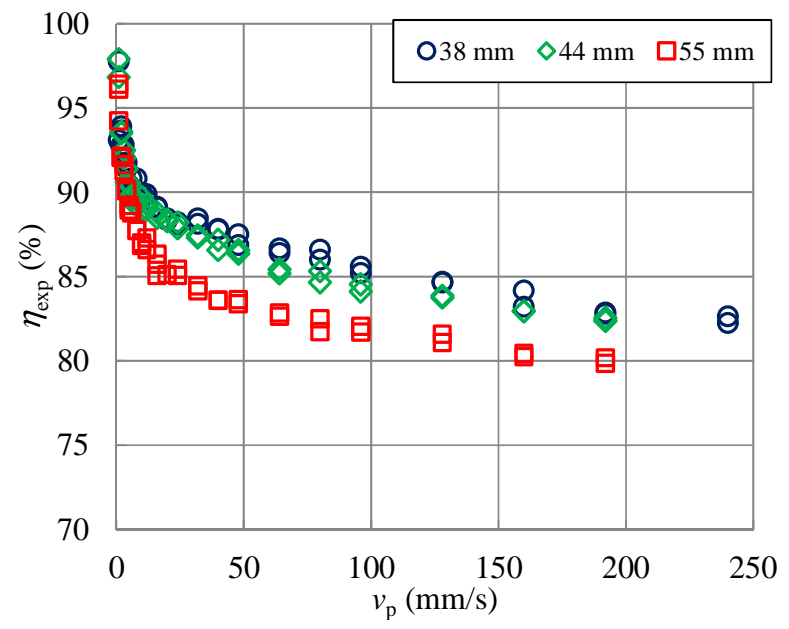

Fig. 12 Adiabatic efficiency for $v_{\mathrm{p}}=1-192 \mathrm{~mm} / \mathrm{s}, T_{0}=$ $100{ }^{\circ} \mathrm{C}$ and $D_{\mathrm{p}}=38,44,55 \mathrm{~mm}$. 


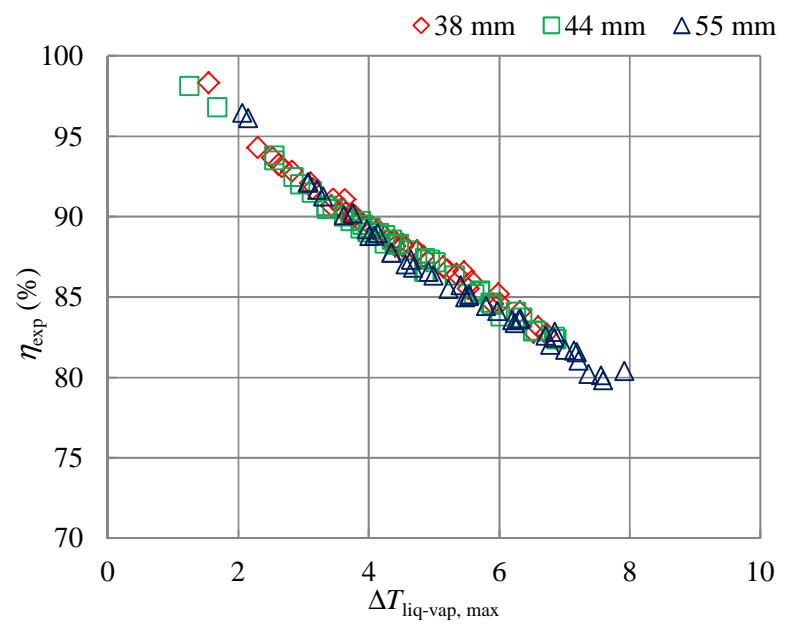

Fig. 13 Effect of maximum temperature difference for $v_{\mathrm{p}}$ $=1-192 \mathrm{~mm} / \mathrm{s}, T_{0}=100{ }^{\circ} \mathrm{C}$ and $D_{\mathrm{p}}=38,44,55 \mathrm{~mm}$.

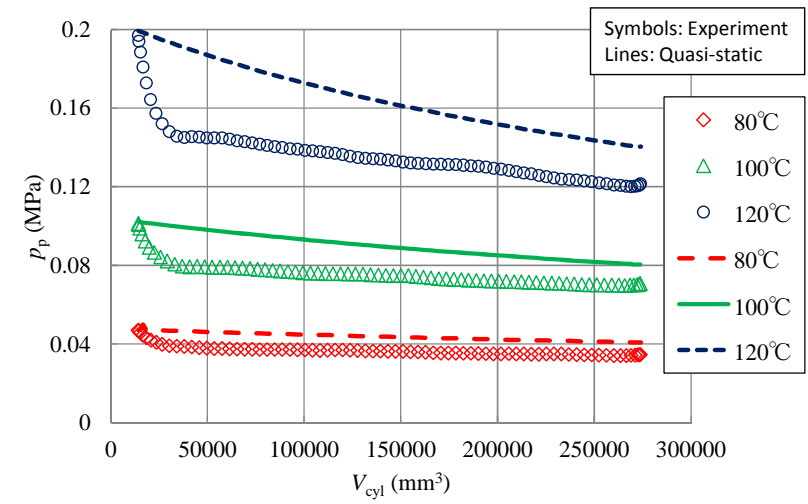

Fig. $14 P-V$ diagram for $v_{\mathrm{p}}=128 \mathrm{~mm} / \mathrm{s}, D_{\mathrm{p}}=44 \mathrm{~mm}$ and $T_{0}=80,100,120{ }^{\circ} \mathrm{C}$.

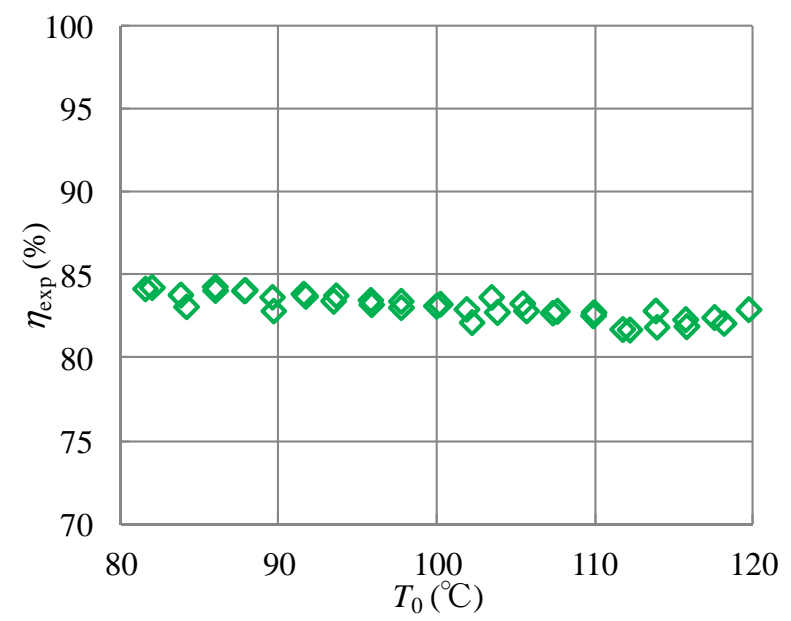

Fig. 15 Adiabatic efficiency versus initial temperature for $v_{\mathrm{p}}=128 \mathrm{~mm} / \mathrm{s}, D_{\mathrm{p}}=44 \mathrm{~mm}$. 


\section{Pressure change prediction during two-phase expansion}

A model to predict the pressure change is proposed. Figure 16 shows the temperature distribution in the cylinder. In this model, it is assumed that the evaporated vapor is a saturated vapor and is generated from the liquid-vapor interface. The vapor phase temperature is assumed to be constant and equal to the interface temperature. To simplify the phenomena, one dimensional thermal conduction model Eq. (13) is proposed. At the liquid-vapor interface, heat conduction balances with the latent heat of evaporation, so the boundary condition of second kinds is defined as shown in Eq. (14). The evaporated vapor mass $\mathrm{d} m_{\text {vap }}$ generated from the interface is calculated from Eqs. (13) and (15). At $t=$ 0 , evaporated vapor mass $\mathrm{d} m_{\text {vap }}$ is 0 and there is no temperature distribution.

In actual expansion, liquid phase is agitated by boiling bubbles or by natural convection. To model the agitation effect, the effective thermal conductivity is introduced, and it is assumed that the liquid phase effective thermal conductivity can be expressed by the agitation factor $\beta$ as shown in Eq (16). In Eqs. (13) and (16), interface area $S_{\mathrm{p}}$ is equal to the surface area of the piston. In boiling condition, interface area between liquid and vapor is increased by the boiling bubble. Effective interface area $S_{\text {eff }}$ is the value which considers the effect of boiling bubbles. The local liquid temperature is calculated by using this effective thermal conductivity.

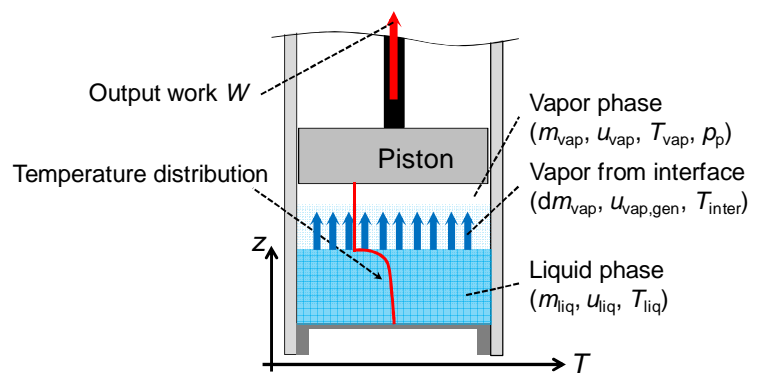

Fig. 16 Temperature gradient in the cylinder

$$
\begin{aligned}
& \rho_{\text {liq }} S_{\mathrm{p}} C_{\mathrm{p}} \frac{\partial T_{\text {liq }}}{\partial t}=S_{\text {eff }} \lambda_{\text {liq,eff }} \frac{\partial^{2} T_{\text {liq }}}{\partial z_{\text {liq }}{ }^{2}} \\
& -S_{\text {eff }} \lambda_{\text {liq,eff }}\left(\frac{\partial T_{\text {liq }}}{\partial z_{\text {liq }}}\right)_{z_{\text {liq }}=z_{\text {liq }, \text { inter }}}=l_{\mathrm{v}} \frac{\mathrm{d} m_{\mathrm{v}}}{\mathrm{d} t} \\
& \begin{aligned}
\left(m_{\mathrm{vap}}+\mathrm{d} m_{\text {vap }}\right) & u_{\text {vap }} \\
& =m_{\text {vap }} u_{\text {vap }}^{\prime}+d m_{\text {vap }} u_{\text {vap,gen }} \\
& -d W
\end{aligned}
\end{aligned}
$$

$S_{\text {eff }} \lambda_{\text {liq,eff }}=(1+\beta) \times S_{\mathrm{p}} \lambda_{\text {liq }}$

The physical quantities related to boiling bubbles are gravity $g$, piston diameter $D_{\mathrm{p}}$, bubble diameter $D_{\mathrm{b}}$, liquid-vapor density difference $\Delta \rho$ and liquid viscosity $\mu_{\text {liq }}$, as shown in Eq. (17). The vapor density is very small enough compared to the liquid density, so the density difference is approximated by the liquid density $\rho_{\text {liq }}$. The bubble diameter used in this model is obtained from Cole's correlation [18-19], shown in Eq. (18). Bond and Jakob numbers used in Eq. (18) are defined in Eqs. (19) and (20), respectively. The Cole's correlation can be applied for saturated pool boiling in the 
atmospheric or sub-atmospheric pressure. In this correlation, $B o^{1 / 2}$ which is the dimensionless departure diameter of bubbles is expressed as a function of $J a$ which is the ratio of sensible heat to latent heat absorbed during the liquid-vapor phase change. In the present study, the bubbles are generated from the bottom surface of the cylinder. It is assumed that the bubble departure phenomenon is similar to that in pool boiling, and Cole's correlation is used to obtain the bubble diameter. By the dimensional analysis using Pi theorem, the agitation factor is expressed as Eq. (21). The agitation factor $\beta$ is set to 0 at $t=0$. Coefficients in Eq. (21) are fitted as $n_{1}=6.5 \times 10^{5}, n_{2}=0.4$, and $n_{3}=5.0$ from the experimental data for $v_{\mathrm{p}}=1-192 \mathrm{~mm} / \mathrm{s}, T_{0}=100{ }^{\circ} \mathrm{C}$ and $D_{\mathrm{p}}=38,44,55 \mathrm{~mm}$.

$\beta=f\left(g, D_{\mathrm{p}}, D_{\mathrm{b}}, \Delta \rho, \mu_{\text {liq }}\right)$

$B o^{\frac{1}{2}}=0.04 \mathrm{Ja}$

$B o=\frac{D_{b}^{2} g\left(\rho_{\mathrm{liq}}-\rho_{\mathrm{vap}}\right)}{\sigma_{\mathrm{liq}}}$

$J a=\frac{\rho_{\text {liq }} C_{\mathrm{p}} \Delta T_{\mathrm{sat}}}{\rho_{\mathrm{vap}} l_{\mathrm{v}}}$

$\beta=n_{1}\left(\frac{g \rho_{\mathrm{liq}}{ }^{2} D_{\mathrm{b}}{ }^{3}}{\mu_{\mathrm{liq}}{ }^{2}}\right)^{n_{2}}\left(\frac{D_{\mathrm{b}}}{D_{\mathrm{p}}}\right)^{n_{3}}$

$$
n_{1}=6.5 \times 10^{5}, n_{2}=0.4, n_{3}=5.0
$$

Figure 17 shows the predicted and measured $P-V$ diagrams for $T_{0}=100{ }^{\circ} \mathrm{C}, D_{\mathrm{p}}=44 \mathrm{~mm}$. The present model can predict well the initial rapid pressure decrease. In this model, the expansion process starts without boiling bubbles at the beginning of expansion. So the effect of agitation is weak and the gas-liquid interface temperature is decreased only by evaporation at the interface, which causes initial rapid decrease of pressure. After this initial pressure reduction, boiling bubbles are generated at the bottom of the cylinder and the liquid phase is agitated, which results in moderate decrease of the interface temperature. Figure 18 shows the comparison between predicted and measured pressures. As shown in Fig. 18, the present model can predict the pressure within $\pm 5.0 \%$ accuracy.

Figure 19 shows predicted and measured adiabatic efficiencies for $v_{\mathrm{p}}=1-240 \mathrm{~mm} / \mathrm{s}, T_{0}=100{ }^{\circ} \mathrm{C}$ and $D_{\mathrm{p}}=38,44$, $55 \mathrm{~mm}$. The model predictions match well with the experimental results. In this model, the agitation effect increases and the adiabatic efficiency is enhanced as the piston diameter becomes smaller. Figure 20 shows the comparison between experimental results and model prediction. As shown in Fig. 20, the present model can predict adiabatic efficiency within the range of about $\pm 2.5 \%$ accuracy.

From these results, the temperature uniformity in the liquid phase probably affects the pressure drop strongly. In order to improve the adiabatic efficiency, it is important to homogenize the liquid phase temperature. 


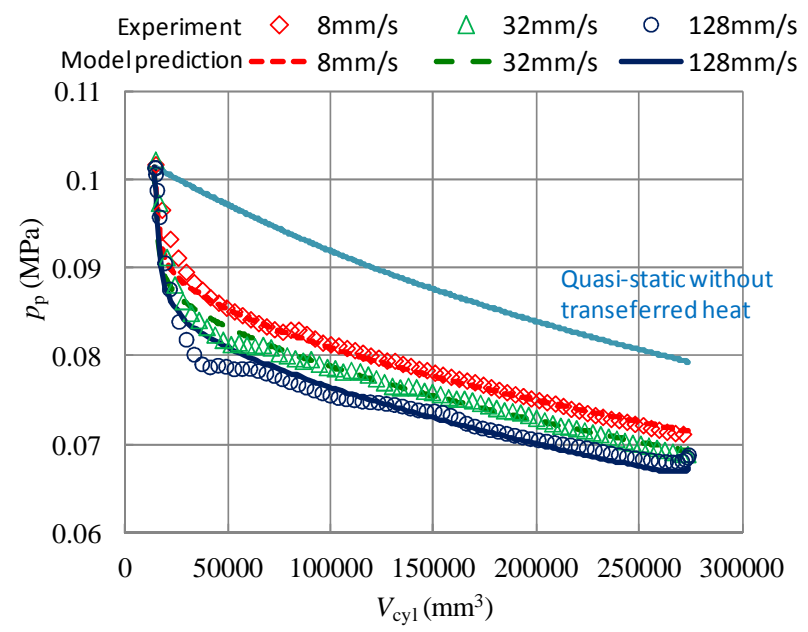

Fig. 17 Predicted and measured $P-V$ diagram for $T_{0}=$ $100{ }^{\circ} \mathrm{C}, D_{\mathrm{p}}=44 \mathrm{~mm}$.

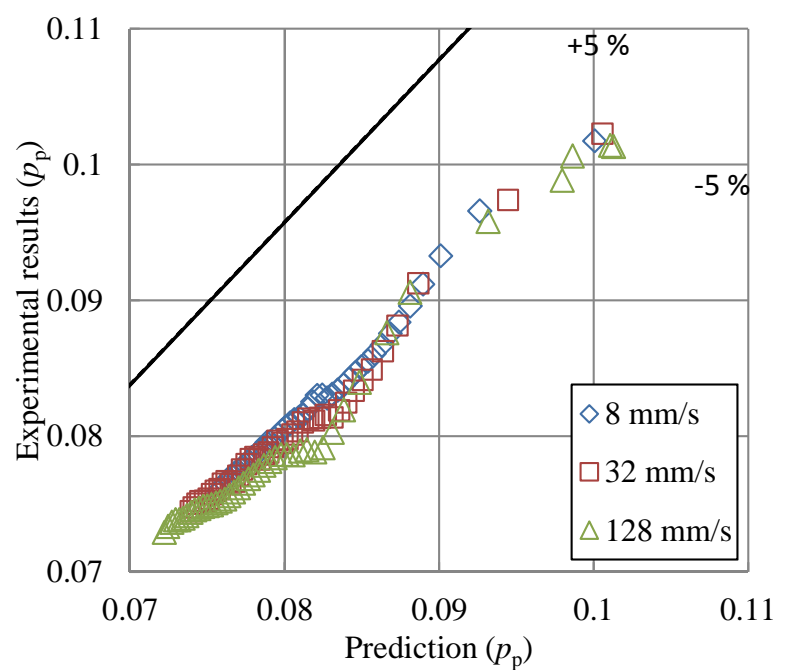

Fig. 18 Comparison between predicted and measured pressure for $T_{0}=100{ }^{\circ} \mathrm{C}, D_{\mathrm{p}}=44 \mathrm{~mm}$.

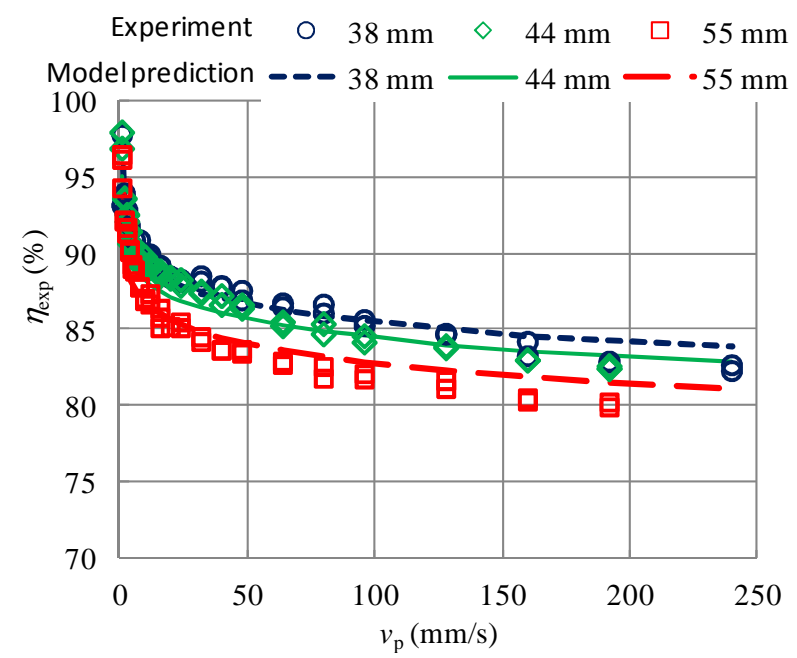

Fig. 19 Predicted and measured adiabatic efficiency for $v_{\mathrm{p}}=1-240 \mathrm{~mm} / \mathrm{s}, T_{0}=100{ }^{\circ} \mathrm{C}$ and $D_{\mathrm{p}}=38,44,55 \mathrm{~mm}$. 


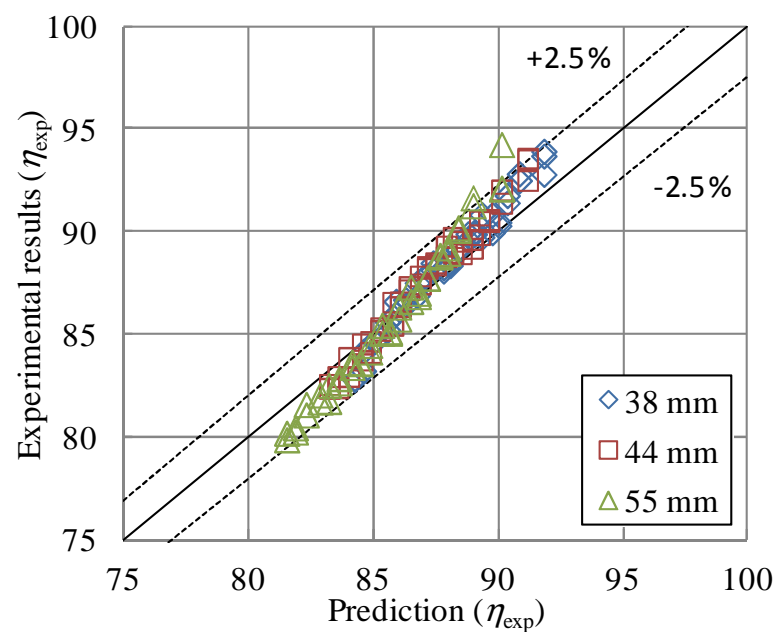

Fig. 20 Comparison between prediction and experimental results for $v_{\mathrm{p}}=1-240 \mathrm{~mm} / \mathrm{s}, T_{0}=100{ }^{\circ} \mathrm{C}$ and $D_{\mathrm{p}}=38$, $44,55 \mathrm{~mm}$.

\section{Conclusion}

An adiabatic two-phase expansion experiment in a cylinder with moving piston is conducted and the model for pressure change is proposed. From the experimental results and model analysis, following conclusions are obtained.

(a) Boiling bubbles are generated at the edge of the cylinder. The effect of boiling bubbles generated in the liquid phase increase as the piston velocity increases and as the piston diameter decreases.

(b) The adiabatic efficiency decreases as the piston velocity is increased because of the lack of phase change due to high-piston velocity.

(c) The adiabatic efficiency decreases as the piston diameter are increased. Boiling bubbles are mostly generated from the corner of the cylinder and agitation effect of the liquid phase is stronger for the case of smaller piston diameter. It is considered that this liquid phase agitation strongly affects the adiabatic efficiency.

(d) The proposed model with effective liquid thermal diffusivity can predict well the pressure change and adiabatic efficiency, and can predict adiabatic efficiency within the range of about $\pm 2.5 \%$ accuracy. It is considered that the temperature uniformity in the liquid phase strongly affects the pressure drop.

\section{Acknowledgement}

This work has been partly supported by the Japan Science and Technology Agency (JST). The authors gratefully acknowledge them for financial support of this work.

\section{References}

1. J. Fischer, Comparison of trilateral cycles and organic Rankine cycles, Energy 36 (2011), pp. 6208 - 6219. 
2. C. Zamfirescu \& I. Dincer, Thermodynamic analysis of a novel ammonia-water trilateral Rankine cycle, Thermochimica Acta 477 (2008), pp. 7 - 15.

3. T. Ho, S. S. Mao \& R. Greif, Comparison of the Organic Flash Cycle (OFC) to other advanced vapor cycles for intermediate and high temperature waste heat reclamation and solar thermal energy, Energy 42 (2012), pp. 213 223.

4. N. A. Lai \& J. Fischer, Efficiencies of power flash cycles, Energy 44 (2012), pp. 1017 - 1027.

5. H.Ohman \& P. Lundqvist, Experimental investigation of a Lysholm Turbine operating with superheated, saturated and 2 - phase inlet conditions, Applied Thermal Engineering 50 (2013), pp. 1211 - 1218.

6. S. Clemente, D. Micheli, M. Reini \& R. Taccani, Energy efficiency analysis of Organic Rankine cycles with scroll expanders for cogenerative applications, Applied Energy 97 (2012), pp. 792 - 801.

7. J. Bao \& L. Zhao, A review of working fluid and expander selections for organic Rankine cycle, Renewable and sustainable Energy Reviews 24 (2013), pp. 325 - 342.

8. I.K. Smith, Development of the trilateral flash cycle system. 1. Fundamental considerations., Journal of Power and Energy 207 (1993), pp. 179-194.

9. I.K. Smith \& R.P.M. Dasilva, Development of the trilateral flash cycle system. 2. Increasing power output with working fluids mixtures, Journal of Power and Energy 208 (1994), pp. 135-144.

10. I.K. Smith, N. Stosic \& C.A. Aldis, Development of the trilateral flash cycle system. 3. The design of high-efficiency two-phase screw ex panders, Journal of Power and Energy 210 (1996), pp. 75-93.

11. M. Oreijah, A. Date \& A. Akbarzadaha, Comparison between Rankine Cycle and Trilateral Cycle in Binary System for Power Generation, Applied Mechanics and Materials 464 (2014), pp 151-155.

12. M. Steffen, M. Lofffler \& K. Schaber, Efficiency of a new Triangle Cycle with flash evaporation in a piston engine, Energy, Vol.57 (2013), pp. 295-307.

13. J. Yan, D. Zhang, D. Chong, G. Wang, L. Li, Experimental study on static/circulatory flash evaporation, International Journal of Heat and Mass Transfer 53 (2010), pp 5528-5535.

14. D. Zhang, D. Chong, J. Yan, Y. Zhang, Study on steam-carrying effect in static flash evaporation, International Journal of Heat and Mass Transfer 55 (2012), pp 4487-4497.

15. D. Saury, S. Harmand, M. Siroux, Flash evaporation from a water pool:Influence of the liquid height and of the depressurization rate, International Journal of Thermal Sciences 44 (2005), pp 953-965.

16. S. Mutair, Y. Ikegami, Experimental study on flash evaporation from superheated water jets: Influencing factors and formulation of correlation, International Journal of Heat and Mass Transfer 52 (2009), pp 5643-5651.

17. E.W. Lemmon, M.L. Huber \& M.O. McLinden, NIST standard reference database 23: reference fluid thermodynamic and transport properties e REFPROP version 9.0. Gaithersburg: National Institute of Standards and Technology, Standard Reference Data Program; 2010.

18. R.Cole, Frequency and departure diameter at sub-atmospheric pressures. AIChE J. 13(1967), pp 779-783.

19. J. Kim, M.H. Kim, On the departure behaviors of bubble at nucleate pool boiling, International Journal of Multiphase Flow 32 (2006), pp1269-1286. 